\title{
Antibody-induced secondary treatment failure in a patient treated with botulinum toxin type $\mathrm{A}$ for glabellar frown lines
}

This article was published in the following Dove Press journal:

Clinical Interventions in Aging

8 November 2011

Number of times this article has been viewed

\section{Gabriele Stengel \\ Eva Kristina Bee}

Hautarztpraxis Stengel and Bee, Münster, Germany
Correspondence: Gabriele Stengel Hautarztpraxis Stengel and Bee, Rothenburg 50, 48I43 Münster, Germany

Tel +4902514497 I

Fax +490 25I4 0786

Email praxis@stengelundbee.de

\begin{abstract}
Botulinum toxin type A (BTX-A) preparations are widely used nonsurgical treatments for facial wrinkles. Higher doses of BTX-A are also used for therapeutic purposes in the treatment of conditions involving increased muscle tone, such as cervical dystonia. The phenomenon of antibody-induced treatment failure is well known in the therapeutic setting, but reports are also emerging following cosmetic use of BTX-A. We describe the case of a 41-year-old female nurse who developed secondary treatment failure during 6 years of BTX-A treatment for glabellar lines. After a good response to the first BTX-A injection, the intensity and duration of effect decreased after subsequent treatments. Antibody tests revealed a high titer of neutralizing anti-BTX-A antibodies. This case shows secondary treatment failure due to the production of neutralizing antibodies following administration of BTX-A formulations for cosmetic purposes and demonstrates that immunogenicity of BTX-A preparations is an important consideration, even in the cosmetic setting.
\end{abstract}

Keywords: botulinum toxin type A, neutralizing antibodies, antibody-induced treatment failure

\section{Introduction}

Botulinum toxin type A (BTX-A) preparations are commonly used in therapeutic and cosmetic applications with great success. However, after initial good responses, therapy can subsequently fail either partially or completely (secondary therapy failure) due to a number of causes, including inadequate dosage, injection of inappropriate muscles, and development of BTX-A neutralizing antibodies. ${ }^{1,2}$ Antibody-induced treatment failure following treatment with BTX-A for therapeutic purposes has been reported to range from $4 \%$ to $10 \%$ of patients treated ${ }^{3,4}$ and to decrease to $1 \%-6 \%$ after the foreign protein load of the preparation used is reduced. 5,6 The risk of developing antibody-induced treatment failure has been shown to increase with short injection intervals and high injected doses. ${ }^{2,7}$ Despite lower BTX-A dosages being used in cosmetic applications compared with therapeutics, there are now emerging reports of antibody-induced treatment failure in facial esthetics. ${ }^{8,9}$

\section{Case report}

Here we report the case of a 41-year-old Caucasian woman who had been receiving BTX-A preparations for the treatment of glabellar lines for 6 years (Table 1). She was initially treated in 2004 with a commercially available BTX-A preparation, abobotulinumtoxinA (Dysport ${ }^{\circledR}$, Ipsen Ltd, Slough, UK). The effects of treatment lasted for 3-4 months. However, following her next treatment with 
Table I Treatment history

\begin{tabular}{|c|c|c|c|c|c|}
\hline Date & BTX-A preparation & Dosage & Area treated & Duration of effect & $\begin{array}{l}\text { Approximate } \\
\text { treatment interval }\end{array}$ \\
\hline 2004 & Abobotulinumtoxin $A$ & N/A & Glabellar & $\begin{array}{l}\text { First treatment: } 12-16 \text { weeks; } \\
\text { Second treatment: maximum } \\
8 \text { weeks }\end{array}$ & 6 months \\
\hline 2005 & AbobotulinumtoxinA & N/A & Glabellar & $4-8$ months & 6 months \\
\hline 2006 & Abobotulinumtoxin $A$ & N/A & Glabellar & 3-4 weeks & 6 months \\
\hline 2007 & AbobotulinumtoxinA & N/A & Glabellar & $3-4$ weeks & 6 months \\
\hline 2008 & AbobotulinumtoxinA & N/A & Glabellar & $3-4$ weeks & 6 months \\
\hline February II, 2009 & OnabotulinumtoxinA & $28 \cup$ & Glabellar & $\begin{array}{l}\text { Patient complained } \\
\text { of incomplete treatment }\end{array}$ & N/A \\
\hline February 25, 2009 & OnabotulinumtoxinA & $9 \cup$ & Glabellar, periorbital & $2-3$ weeks & 1.5 months \\
\hline May 28, 2009 & OnabotulinumtoxinA & $10 \mathrm{U}$ & Glabellar, periorbital & $2-3$ weeks & 3 months \\
\hline August 26, 2009 & IncobotulinumtoxinA & $20 U$ & Glabellar, periorbital & 3-4 weeks & 3 months \\
\hline December 24, 2009 & IncobotulinumtoxinA & $22 \cup$ & Glabellar, periorbital & $3-4$ weeks & 4 months \\
\hline January 19, 2010 & IncobotulinumtoxinA & $44 U$ & Glabellar, periorbital & 3-4 weeks & I month \\
\hline
\end{tabular}

Abbreviations: N/A, not available; BTX-A, botulinum toxin type $A$.

abobotulinumtoxinA in the glabellar region, the duration of effect was reduced to 8 weeks. From 2005 to 2008, prior to presentation at our clinic, the patient received further injections of abobotulinumtoxinA in the glabellar area twice yearly and reported that the duration of effect subsequently diminished to a maximum effect of 3-4 weeks' duration. From the beginning of 2009, we treated this patient with other BTX-A preparations, first with onabotulinumtoxinA $\left(\right.$ Botox $^{\circledR} /$ Vistabe $^{\circledR}$, Allergan, Irvine, CA), and more recently with incobotulinumtoxinA (Xeomin ${ }^{\circledR} /$ Bocouture $^{\circledR}$, Merz Pharmaceuticals GmbH, Frankfurt, Germany).

The first treatment in our clinic was $28 \mathrm{U}$ of onabotulinumtoxinA in the glabellar area, but the treatment was suboptimal and the patient returned approximately 2 weeks later, when she received an additional $9 \mathrm{U}$ of onabotulinumtoxinA. For this second treatment and subsequent treatments, BTX-A was injected in the periorbital region as well as the glabellar region at the patient's request. The patient reported the duration of effect to be 2-3 weeks. Three months later, the patient received one further treatment in the glabellar and periorbital areas, with $10 \mathrm{U}$ onabotulinumtoxinA, a lower dose than usual, as requested by the patient. However, the patient was still dissatisfied with the treatment outcome and duration of effect. Therefore, we changed to administration of incobotulinumtoxinA at a higher dose $(20 \mathrm{U})$ into the glabellar and periorbital regions, but the duration of effect was only 3-4 weeks. Indeed, two subsequent injections of incobotulinumtoxinA at higher doses (22 $\mathrm{U}$ and $44 \mathrm{U}$ ) also failed to elicit a response of longer duration. The clinical photograph taken approximately 1 month after the final injection shows no remaining effect of neurotoxin (Figure 1C).
Therefore, we considered the possibility that the patient had neutralizing anti-BTX-A antibodies. This seemed likely since neutralizing anti-BTX-A antibodies would not be overcome by switching to another BTX-A formulation, and high antibody titers could prevent a response even to larger doses.

In December 2009, the patient's serum was tested for the presence of neutralizing anti-BTX-A antibodies at a specialized laboratory (Toxogen $\mathrm{GmbH}$, Hannover, Germany) using an in vitro mouse hemidiaphragm assay. ${ }^{10}$ The patient was positive for a high titer of neutralizing antibodies, suggesting that the cause of the secondary therapy failure experienced by this patient was neutralizing anti-BTX-A antibodies.

In this example, following treatment with a complexing protein-containing BTX-A formulation, the patient developed neutralizing antibodies and subsequently did not respond to any of the BTX-A formulations tested. Resistance that develops following the cosmetic use of BTX-A may impact on the success of any subsequent therapeutic BTX-A treatment (eg, for poststroke spasticity) that the patient may need in the future. It also limits further esthetic use of BTX-A. Some clostridial complexing proteins have been found to enhance antibody production, ${ }^{11}$ and may therefore increase the risk of neutralizing anti-BTX-A antibodies. Indeed, reducing the foreign protein load of the early preparation of onabotulinumtoxinA decreased the risk of neutralizing anti-BTX-A antibodies. ${ }^{4} \mathrm{~A}$ further reduction in the protein load of BTX-A injections, for instance by using highly purified formulations, ${ }^{12}$ may be beneficial in patients receiving several cycles of BTX-A injections.

For this patient, switching to a botulinum toxin type B (BTX-B) preparation was not considered because the data show that BTX-B has a greater diffusion potential ${ }^{13}$ and a 

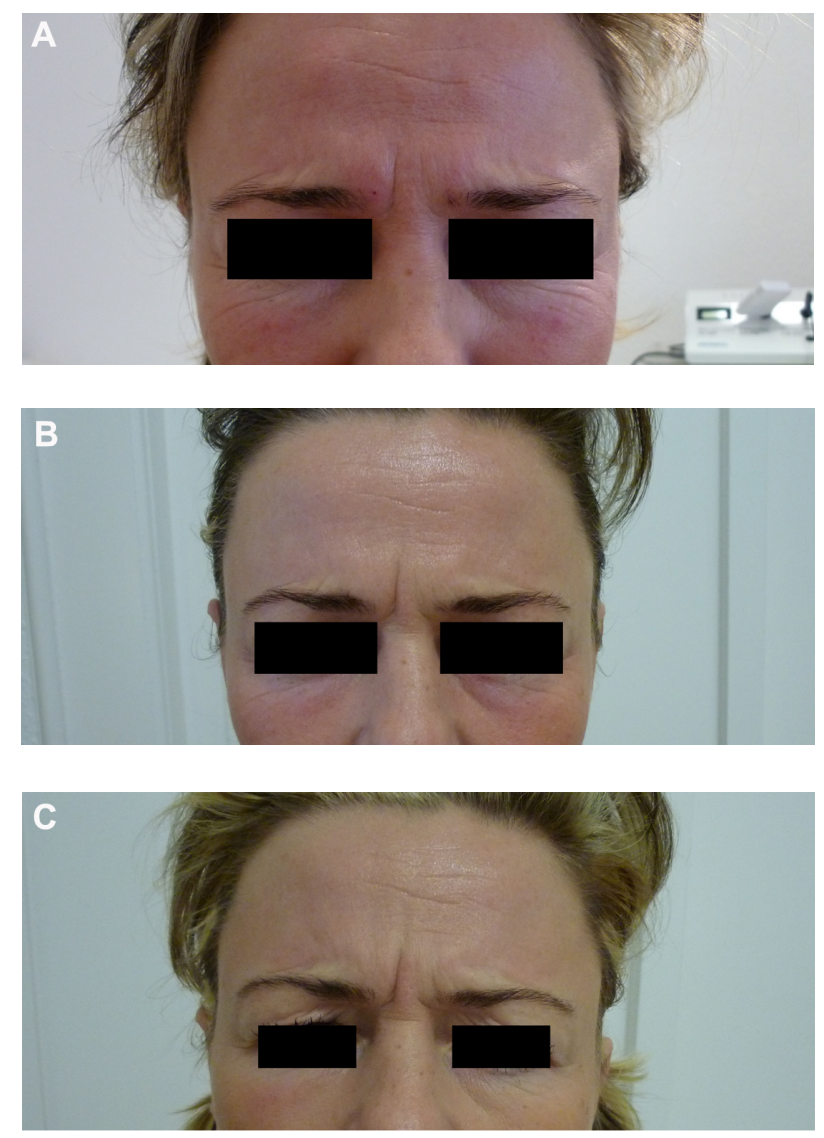

Figure I Clinical photographs taken at maximum frown. (A) Patient prior to injection with incobotulinumtoxinA on December 24, 2009, after developing nonresponsiveness to preparations containing botulinum toxin complex. (B) Patient following injection with incobotulinumtoxinA on January 19, 20I0, after the patient developed nonresponsiveness to preparations containing botulinum toxin complex. (C) Patient on February 25, 2010, about I month after the final botulinum toxin type A injection on January 19, 2010.

highly-acidic $\mathrm{pH},{ }^{12}$ and therefore is associated with more side effects. ${ }^{12}$ Also, the duration of effect seen with BTX-B is not maintained for as long as that observed with BTX-A. ${ }^{14}$ Currently, there is no BTX-B preparation that is approved for an esthetic indication and, consequently, it is not commonly used for this purpose.

Although initial reports stated that less than $1 \%$ of patients develop neutralizing anti-BTX-A antibodies in esthetics, ${ }^{15-17}$ this case, and others like it, ${ }^{8,9}$ highlight the fact that immunogenicity of BTX-As and neutralizing antiBTX-A antibodies are still important issues. Indeed, recent reports monitored BTX-A neutralizing antibodies in patients receiving 1-10 cycles of BTX-A injections, with few patients achieving the maximum number of cycles. ${ }^{15-17}$ Therefore, the long-term effects of BTX-A on neutralizing anti-BTX-A antibody development still need to be investigated to estimate accurately the incidence and importance of neutralizing
anti-BTX-A antibodies in esthetics. This is of particular significance given the widespread offlabel use of BTX-A for cosmetic indications, ${ }^{18,19}$ and the administration of BTX-A preparations by nonmedically trained individuals.

\section{Acknowledgment}

Funding for preparation of this manuscript was provided by Merz Pharmaceuticals GmbH; editorial support was provided by Ogilvy 4D.

\section{Disclosures}

EKB is a consultant for Merz Pharmaceuticals GmbH. GS has no conflicts of interest to disclose in this work.

\section{References}

1. Jankovic J, Schwartz K. Response and immunoresistance to botulinum toxin injections. Neurology. 1995;45(9):1743-1746.

2. Dressler D. Clinical presentation and management of antibody-induced failure of botulinum toxin therapy. Mov Disord. 2004;19 Suppl 8: S92-S100.

3. Greene P, Fahn S, Diamond B. Development of resistance to botulinum toxin type A in patients with torticollis. Mov Disord. 1994;9(2): 213-217.

4. Jankovic J, Vuong KD, Ahsan J. Comparison of efficacy and immunogenicity of original versus current botulinum toxin in cervical dystonia. Neurology. 2003;60(7):1186-1188.

5. Muller K, Mix E, Adib Saberi F, Dressler D, Benecke R. Prevalence of neutralising antibodies in patients treated with botulinum toxin type A for spasticity. J Neural Transm. 2009;116(5):579-585.

6. Brin MF, Comella CL, Jankovic J, Lai F, Naumann M. Long-term treatment with botulinum toxin type A in cervical dystonia has low immunogenicity by mouse protection assay. Mov Disord. 2008;23(10): 1353-1360.

7. Lange O, Bigalke H, Dengler R, Wegner F, deGroot M, Wohlfarth K. Neutralizing antibodies and secondary therapy failure after treatment with botulinum toxin type A: Much ado about nothing? Clin Neuropharmacol. 2009;32(4):213-218.

8. Borodic G. Immunologic resistance after repeated botulinum toxin type A injections for facial rhytides. Ophthal Plast Reconstr Surg. 2006;22(3):239-240.

9. Lee S-K. Antibody-induced failure of botulinum toxin type A therapy in a patient with masseteric hypertrophy. Dermatol Surg. 2007; 33(1 Spec No.):S105-S110.

10. Göschel H, Wohlfarth K, Frevert J, Dengler R, Bigalke H. Botulinum A toxin therapy: Neutralizing and nonneutralizing antibodies - therapeutic consequences. Exp Neurol. 1997;147(1):96-102.

11. Lee JC, Yokota K, Arimitsu H, et al. Production of anti-neurotoxin antibody is enhanced by two subcomponents, HA1 and HA3b, of Clostridium botulinum type B $16 \mathrm{~S}$ toxin-haemagglutinin. Microbiology. 2005;151(Pt 11):3739-3747.

12. Carruthers A, Carruthers J. Botulinum toxin products overview. Skin Therapy Lett. 2008;13(6):1-4.

13. Flynn TC, Clark RE 2nd. Botulinum toxin type B (Myobloc) versus botulinum toxin type A (Botox) frontalis study: Rate of onset and radius of diffusion. Dermatol Surg. 2003;29(5):519-522.

14. Flynn TC. Botulinum toxin: Examining duration of effect in facial aesthetic applications. Am J Clin Dermatol. 2010;11(3):183-199.

15. Kawashima M, Harii K. An open-label, randomized, 64-week study repeating 10- and 20-U doses of botulinum toxin type $\mathrm{A}$ for treatment of glabellar lines in Japanese subjects. Int J Dermatol. 2009;48(7):768-776. 
16. Lawrence I, Moy R. An evaluation of neutralizing antibody induction during treatment of glabellar lines with a new US formulation of botulinum neurotoxin type A. Aesthet Surg J. 2009;29(6 Suppl):S66-S71.

17. Monheit G, Carruthers A, Brandt F, Rand R. A randomized, doubleblind, placebo-controlled study of botulinum toxin type A for the treatment of glabellar lines: Determination of optimal dose. Dermatol Surg. 2007;33(1 Spec No.):S51-S59.
18. Cheng CM, Chen JS, Patel RP. Unlabeled uses of botulinum toxins: A review, Part 1. Am J Health Syst Pharm. 2006;63(2):145-152.

19. Cheng CM, Chen JS, Patel RP. Unlabeled uses of botulinum toxins: A review, Part 2. Am J Health Syst Pharm. 2006;63(3):225-232.

\section{Publish your work in this journal}

Clinical Interventions in Aging is an international, peer-reviewed journal focusing on evidence-based reports on the value or lack thereof of treatments intended to prevent or delay the onset of maladaptive correlates of aging in human beings. This journal is indexed on PubMed Central, MedLine, the American Chemical Society's 'Chemical Abstracts Ser- vice' (CAS), Scopus and the Elsevier Bibliographic databases. The manuscript management system is completely online and includes a very quick and fair peer-review system, which is all easy to use. Visit $\mathrm{http}: / / \mathrm{www}$.dovepress.com/testimonials.php to read real quotes from published authors.

Submit your manuscript here: http://www.dovepress.com/clinical-interventions-in-aging-journal 